\title{
Modeling of a re-heat two-stage adsorption chiller by Al approach
}

\author{
Jaroslaw Krzywanski ${ }^{1, *}$, Karolina Grabowska ${ }^{1}$, Marcin Sosnowski ${ }^{1}$, Anna Żyłka ${ }^{1}$, Karol Sztekler ${ }^{2}$, Wojciech Kalawa ${ }^{2}$, \\ Tadeusz Wójcik², and Wojciech Nowak ${ }^{2}$ \\ ${ }^{1}$ Jan Dlugosz University in Czestochowa, Faculty of Mathematics and Natural Sciences, Armii Krajowej 13/15, 42-200 \\ Czestochowa, Poland \\ ${ }^{2}$ AGH University of Science and Technology, Faculty of Energy and Fuels, Czarnowiejska 30, 30-059 Krakow, Poland
}

\begin{abstract}
A distinct advantage of adsorption chillers is their ability to be driven by heat of near ambient temperature. However the performance of the thermally driven adsorption systems is lower than that of other heat driven heating/cooling systems. It is the result of a poor heat transfer coefficient between the bed and the immersed heating surfaces of a built-in heat exchanger system. The aim of this work is to study the effect of thermal conductance values as well as other design parameters on the performance of a re-heat two-stage adsorption chiller. One of the main energy efficiency factors in cooling production, i.e. cooling capacity (CC) for wide-range of both design and operating parameters is analyzed in the paper. Moreover, the work introduces artificial intelligence (AI) approach for the optimization study of the adsorption cooler. The Adaptive Neuro - Fuzzy Inference System (ANFIS) was employed in the work. The developed ANFIS model can be applied for optimizations purposes and may constitute a submodel or a separate module in engineering calculations, capable to predict the CC of the re-heat two-stage adsorption chiller.
\end{abstract}

\section{Introduction}

The silica gel-water adsorption chillers constitute the economically viable and environmentally friendly technology, capable to convert waste thermal energy into useful cooling [1]. Their main disadvantages, are: the intermittence, bulkiness, and poor thermal conductivity of the used adsorbents leading to the low specific cooling power (SCP) and coefficient of performance (COP) [2].

Since the complexity of multi-bed adsorption chillers operation is still not sufficiently recognized the improvement of total efficiency of adsorption processes is still a challenging task [3-5].

Mathematical modelling is considered as an efficient research approach [6].

However sometimes additional assumptions should be made when modeling to get a trackable solution, the algorithms are often complicated and based on the solution of complex and time consuming sets of differential equations [7-9].

Artificial intelligence (AI) approach can be an alternative method for the above technics of data handling. The most convenient approach is to apply a non-iterative procedure, where one only needs to enter input parameters and call the performed the AI model.

The paper introduces the Adaptive Neuro - Fuzzy Inference System (ANFIS) for modelling of a re-heat two-stage adsorption chiller using low-temperature heat from cogeneration. The developed non-iterative model, using procedure similar to the one given in [10 - 14] allows to describe the behavior of the adsorption cooler and predict one of the main energy efficiency factors in cooling production, i.e. cooling capacity for wide-range of both design and operating parameters.

To our best knowledge we are the first to employ the Adaptive Neuro-Fuzzy Inference System to describe the behavior of the innovative adsorption chiller and predict one of the main energy efficiency factors in cooling production, i.e. cooling capacity (CC) for wide-range of both design and operating parameters.

\section{Analysis and modeling}

\subsection{An object of investigations}

The analyzed re-heat two-stage chiller consists of four adsorbent beds, one evaporator and one condenser as well as metallic tubes for heat transfer fluid and refrigerant flows $[15,16]$. Silica gel is used as sorbent. The schematic diagram of a re-heat two-stage chiller is given in Fig. 1.

Long cycle (3400s) and short cycle (1300 s) are considered during the study. A long cycle time with heat source temperature at $60{ }^{\circ} \mathrm{C}$ is selected in this study. A detailed description of the chiller, including considered operating strategy, can be found elsewhere [15].

\footnotetext{
* Corresponding author: jkrzywanski@tlen.pl
} 


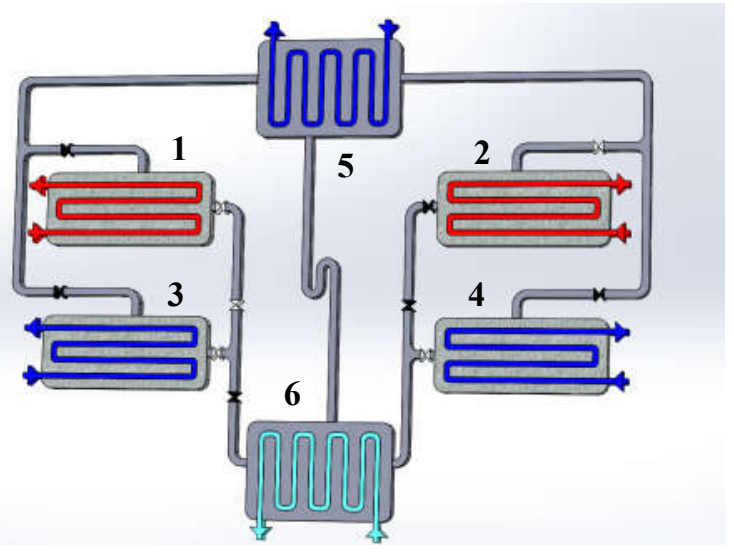

Fig. 1. The scheme of the adsorption chiller; 1-4 - adsorption beds, 5 - condenser, 6 - evaporator

\subsection{The Adaptive Neuro-Fuzzy Inference System}

For the purpose of this paper the experimental results given in $[15,16]$ were used to derive and validate model parameters.

The Matlab ${ }^{\circledR}$ R2018a, with the Neuro-Fuzzy Toolbox is used to develop the model and predict the $\mathrm{CC}$ of the considered re-heat two stage adsorption chiller [17]. The following values: adsorbent mass $\left(\mathrm{M}_{\text {sorb }}\right)$, cycle time $(\mathrm{t})$, hot water temperature (T), adsorbent-to-metal thermal capacitance ratio $\left(\mathrm{C}_{\mathrm{sorb}} / \mathrm{C}_{\mathrm{met}}\right)$, overall evaporator and sorption element thermal conductance $\left(\mathrm{hA}_{\text {evap }}, \mathrm{hA}_{\text {sorb }}\right.$, respectively are assumed as input parameters.

The total number of learning data used to develop model includes 80 samples of which 25 are independent checking data set, similar to the procedure given in $[10$, $11,13]$.

The training the ANFIS model was performed for the following stopping criteria for training: number of training epochs equal to 3000 and the Error Tolerance = 0.1 .

\section{Results and discussion}

The comparison between desired and calculated by the model results revealed that the calculated results are located within the range of $\pm 10 \%$ of relative error, compared to the desired data.

In order to study the influence of a specific operating variable on the cooling capacity, other input parameters have to be fixed and keep unchanged during the analysis.

\subsection{The effect of adsorbent mass on cooling capacity}

The influence of adsorbent mass on cooling capacity can be found in Figure 2. As adsorbent mass increases from $4.7 \mathrm{~kg}$ to $32 \mathrm{~kg}$. the cooling capacity increases due to the increase of bed sorption properties.

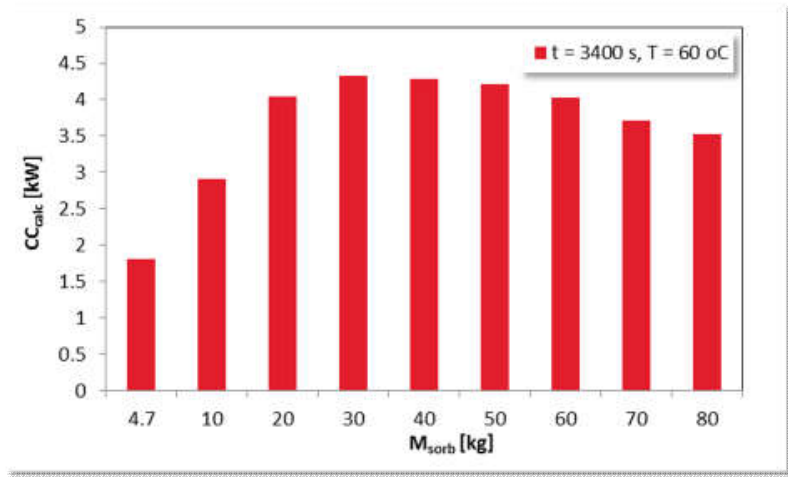

Fig. 2. The influence of adsorbent mass on cooling capacity.

\subsection{The effect of adsorbent mass on cooling capacity}

The influence of thermal conductance of sorption and element and evaporator on $\mathrm{CC}$ is depicted in Fig. 3. Three data series correspond to different values of thermal conductance of evaporator, namely: 1000, 2500 and $4000 \mathrm{~W} \mathrm{~K}^{-1}$.

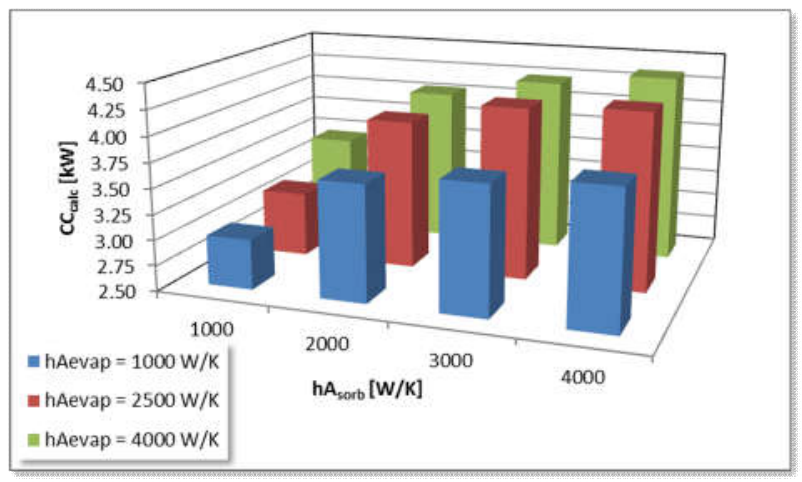

Fig. 3. The effect of sorption element and evaporator thermal conductance on cooling capacity.

The higher sorption element thermal conductance means better heat transfer conditions inside the sorption element and the increase in $\mathrm{hA}_{\text {sorb }}$ allows for better preparation of the bed for the adsorption process.

This also means higher amount of refrigerant inside the bed and better performance, leading to the increase in cooling capacity [15].

Similar explanation applies to the increase in the evaporator thermal conductance.

The performed calculations allows to determine optimal experimental and design parameters.

\section{Conclusions}

The paper deals with an innovative design in cooling production, a re-heat two-stage adsorption chiller.

The maximum relative error of the developed model is lower than $10 \%$.

The developed model constitutes an easy-to-use and powerful optimization tool which allows estimating the cooling capacity of the re-heat two-stage adsorption chiller. 


\section{Nomenclature}

A area

C specific heat capacity

$\mathrm{h}$ heat transfer coefficient

$\mathrm{M}$ mass

$\mathrm{t}$ cycle time

$\mathrm{T}$ hot water temperature

\section{Subscripts}

$\begin{array}{ll}\text { calc } & \text { calculated } \\ \text { evap } & \text { evaporator } \\ \text { met } & \text { metal } \\ \text { sorb } & \text { sorbent }\end{array}$

\section{Acronyms}

AI

ANFIS

$\mathrm{CC}$

COP

SCP

$\mathrm{m}^{2}$
$\mathrm{~J} /(\mathrm{kg} \mathrm{K})$
$\mathrm{W} /\left(\mathrm{m}^{2} \mathrm{~K}\right)$
$\mathrm{kg}$
$\mathrm{s}$
${ }^{\circ} \mathrm{C}$

$\mathrm{m}^{2}$

) $\mathrm{s}$ ${ }^{\circ} \mathrm{C}$
11. J. Krzywański, W. Nowak, Journal of Power Technologies 97, 75-84 (2017)

12. J. Krzywanski, W. Nowak, Int. J. Heat Mass Transf. 94, 327-34 (2016)

13. J. Krzywanski, W. Nowak, J. Energy Eng. 142, 1, Article Number 04015017 (2016)

14. J. Krzywanski, M. Wesolowska, A. Blaszczuk, A. Majchrzak, M. Komorowski, W. Nowak, Procedia Engineering 157, 66 - 71 (2016)

15. M.Z.I. Khan, K.C.A. Alam, B.B. Saha, A. Akisawa, T. Kashiwagi, Appl. Therm. Eng. 27, 1677-1685 (2007)

16. M.Z.I. Khan, K.C.A. Alam, B.B. Saha, Y. Hamamoto, A. Akisawa, T. Kashiwagi, Int. J. Therm. Sci. 45, 511-519 (2006)

17. https://www.mathworks.com/help/fuzzy/

\section{Acknowledgment}

Scientific work was performed within the confines of subsidies granted by the Faculty of Mathematics and Natural Sciences of Jan Dlugosz University in Czestochowa. The support is gratefully acknowledged.

\section{References}

1. X. Wang, Z. He, H.T. Chua, Int. J. Refrig. 52, 3241 (2015)

2. R.P. Sah, B. Choudhury, R.K. Das, Renew. Sustain. Energy Rev. 45, 123-134 (2015)

3. Y.I. Aristov, B. Dawoud, I.S. Glaznev, A. Elyas, Int. J. Heat Mass Transf. 51, 4966-4972 (2008)

4. B. Dawoud, Y. Aristov, Int. J. Heat Mass Transf. 46, 273-281 (2003).

5. B.N. Okunev, A.P. Gromov, L.I. Heifets, Y.I. Aristov, Int. J. Heat Mass Transf. 51, 246-252 (2008)

6. Y.I. Aristov, Int. J. Refrig. 32, 675-686 (2009).

7. W. Muskała, J. Krzywański, T. Czakiert, W. Nowak, Rynek Energii 92, 172-176 (2011)

8. W. Muskała, J. Krzywański, R. Rajczyk, M. Cecerko, B. Kierzkowski, W. Nowak, W. Gajewski, Rynek Energii 87, 97-102 (2010)

9. T. Klajny, J. Krzywanski, W. Nowak, Proc. of the $6^{\text {th }}$ Int. Symp. On coal combustion, Conference: 6th International Symposium on Coal Combustion, (Huazhong Univ Sci Technol, Wuhan, PEOPLES R. CHINA, Dec. 01-04, 148 - 53, 2007)

10. J. Krzywanski, K. Grabowska, F. Herman, P. Pyrka, M. Sosnowski, T. Prauzner, W. Nowak, Energy Convers. Manag. 153, 313-22 (2017) 